\title{
Erratum to: Keratinocyte growth factor in acute lung injury to reduce pulmonary dysfunction - a randomised placebo- controlled trial (KARE): study protocol
}

Laurence J. M. Cross ${ }^{1,2}$, Cecilia M. O'Kane ${ }^{1}$, Cliona McDowell ${ }^{3}$, Jospeh J. Elborn ${ }^{1}$, Michael A. Matthay ${ }^{4,5}$ and Daniel F. McAuley ${ }^{1,2^{*}}$

\section{Erratum}

In the original publication [1] the last sentence under the paragraph "Adverse event management" not correct. The correct version can be found here:

"SAEs that occur between trial entry and up to 28 days after completion of the study drug will be reported".

\begin{abstract}
Author details
'Centre for Infection and Immunity, The Queen's University of Belfast, Health Sciences, Building, 97 Lisburn Road, Belfast BT9 7BL, Northern Ireland.

${ }^{2}$ Regional Intensive Care Unit, Royal Victoria Hospital, Belfast Health and Social Care Trust, Grosvenor Road, Belfast BT12 6BA, Northern Ireland.

${ }^{3}$ Clinical Research Support Centre, Royal Victoria Hospital, Belfast Health and Social Care Trust, Grosvenor Road, Belfast BT12 6BA, Northern Ireland.

${ }^{4}$ Cardiovascular Research Institute, University of California, San Francisco, 505 Parnassus Avenue, M-917, San Francisco, CA 94143-0624, USA. ${ }^{5}$ Departments of Medicine and Anesthesia, University of California, San Francisco, 505

Parnassus Avenue, San Francisco, CA 94143, USA
\end{abstract}

Received: 6 April 2017 Accepted: 6 April 2017

Published online: 11 May 2017

\section{Reference}

1. McAuley DF. Keratinocyte growth factor in acute lung injury to reduce pulmonary dysfunction - a randomised placebo-controlled trial (KARE): study protocol. Trials. 2013;14:10.1186/1745-6215-14-51.

\footnotetext{
* Correspondence: d.f.mcauley@qub.ac.uk

${ }^{1}$ Centre for Infection and Immunity, The Queen's University of Belfast, Health Sciences, Building, 97 Lisburn Road, Belfast BT9 7BL, Northern Ireland ${ }^{2}$ Regional Intensive Care Unit, Royal Victoria Hospital, Belfast Health and Social Care Trust, Grosvenor Road, Belfast BT12 6BA, Northern Ireland Full list of author information is available at the end of the article
} 